\title{
PENERAPAN PENDEKATAN SAINTIFIK DALAM AKTIVITAS BELAJAR PENDIDIKAN JASMANI, OLAHRAGA, DAN KESEHATAN DI SMK NEGERI 4 MALANG
}

\author{
Pinton Setya Mustafa ${ }^{1}$, M.E. Winarno² \\ ${ }^{1,2}$ Pendidikan Olahraga, Universitas Negeri Malang \\ Malang, Indonesia \\ e-mail: pintonsetyamustafa@gmail.com, m.e.winarno.fik@um.ac.id
}

\begin{abstract}
Abstrak
Penelitian ini bertujuan mengevaluasi penerapan pendekatan saintifik dalam aktivitas belajar pendidikan jasmani, olahraga, dan kesehatan (PJOK) pada kurikulum 2013 di SMK Negeri 4 Malang yang meliputi aspek: perencanaan, proses pembelajaran, dan penilaian. Model penelitian evaluasi yang digunakan adalah discrepancy model kemudian dianalisis dengan metode deskriptif kuantitatif. Subjek penelitian ini dengan sampel 3 Guru PJOK dan 191 siswa (yang diajar oleh guru tersebut). Teknik pengumpulan data dan instrumen yang digunakan meliputi: dokumentasi, observasi, dan kuesioner. Hasil penelitian yang telah dilakukan menunjukkan pada aspek perencanaan pembelajaran tergolong sangat baik, sedangkan pada aspek proses pembelajaran dan penilaian hasil belajar masih dalam kategori baik. Berdasarkan hasil secara keseluruhan mengenai penerapan pendekatan saintifik dalam pembelajaran PJOK termasuk kriteria baik. Secara umum rekomendasi yang diberikan yaitu hendaknya perencanaan yang telah disusun juga dilakukan dalam pelaksanaan kegiatan belajar mengajar dan penilaian.
\end{abstract}

Kata-kata kunci: evaluasi, pembelajaran, pendidikan jasmani, pendekatan saintifik

\begin{abstract}
This study aims to evaluate the application of the scientific approach to learning activities in physical education, sports, and health (PESH) in the 2013 curriculum at State Vocational School 4 Malang covering aspects: planning, learning process, and assessment. The evaluation research model used is discrepancy then analyzed with quantitative descriptive methods. The subject of this study was a sample of 3 PESH teachers and 191 students (taught by the teacher). Data collection techniques and instruments used include: documentation, observation, and questionnaires. The results of the research that have been done show that the aspects of learning planning are classified as very good, while the aspects of the learning process and the assessment of learning outcomes are still in the good category. Based on overall results regarding the application of the scientific approach in learning PESH including good criteria. In general, the recommendations given are that planning should also be carried out in the implementation of teaching and learning activities and assessment.
\end{abstract}

Keywords: evaluation, learning, physical education, scientific approach 


\section{PENDAHULUAN}

Sistem pendidikan di Indonesia di atur dalam kebijakan kurikulum. Pendidikan jasmani merupakan mata pelajaran wajib yang terdapat dalam kurikulum pendidikan dasar dan menengah (UU RI No. 20 Tahun 2003). Unsur-unsur internal dalam pendidikan jasmani merupakan komponen dari pendidikan masa anak-anak yang tidak dapat diabaikan, karena konsep tersebut umum dilakukan oleh negara demokrasi (Whitehead et al., 2013: 16). Dalam implementasinya pendidikan jasmani memiliki peraturan tersendiri, beberapa di antaranya berkaitan dengan keselamatan, dan beberapa manajemen, dan kontrol (Martinek \& Hellison, 2009: 125). Pendidikan jasmani dapat menanamkan pengetahuan dan nilai melalui aktivitas fisik yang mencakup pembelajaran dalam pengembangan dan pemeliharaan jasmani, mulai dari latihan fisik sederhana sampai dengan permainan olahraga (Chandler et al., 2002: 153). Pendidikan jasmani, olahraga, dan kesehatan (PJOK) merupakan salah satu pelajaran wajib yang dilaksanakan di berbagai jenjang sekolah, mulai dari SD, SMP, hingga SMA/SMK. PJOK berperan untuk membantu siswa menjadi sehat selama di sekolah (Dharmadi, 2016: 17). PJOK secara signifikan dapat bertujuan untuk mencapai berbagai hasil pendidikan pada peserta didik melalui model pembelajaran yang berbeda yaitu dengan aktivitas fisik (Kirk, 2013: 984). Kurikulum 2013 adalah acuan dasar dalam pelaksanaan pendidikan di Indonesia saat ini.

Faktor penunjang keberhasilan pendidikan salah satunya adalah rancangan kurikulum (Winarno, 2012: 4). Kurikulum adalah segala kegiatan yang terjadi di sekolah baik di dalam maupun di luar kelas berupa inti atau materi yang tersusun secara ilmiah untuk pencapaian tujuan pendidikan di bawah naungan satuan pendidikan (Arifin, 2013: 4). Kurikulum selalu mengalami perubahan yang menyesuaikan perkembangan zaman dan tidak statis. Kurikulum 2013 mengartikan standar kompetensi lulusan (SKL) adalah kompetensi yang mencakup afektif, kognitif, dan psikomotor sebagai tujuan kriteria kualitas lulusan (Sani, 2014: 45). Dalam kurikulum 2013 lebih menekankan pelaksanaan pembelajaran dengan pendekatan saintifik. Hal tersebut diharapkan agar mampu menyesuaikan gaya modern dalam belajar karena sebagai upaya untuk memberikan pengaruh positif dalam perkembangan afektif, kognitif, dan psikomotor individu (Wiyanto, 2017: 218). PJOK dalam kurikulum 2013 tidak hanya sekedar membentuk kesehatan, namun dengan pendekatan saintifik yang terdiri dari: mengamati, menanya, mengasosiasi, mencoba, dan mengkomunikasikan (5M) dalam pembelajaran dapat membentuk jati diri dan karakter pada peserta didik (Basuki, 2016: 124). Untuk itu pembelajaran PJOK di era kurikulum 2013 juga beradaptasi dengan pendekatan saintifik.

$\begin{array}{cc}\text { Adapun } & \text { standar mengenai } \\ \text { pelaksanaan } & \text { pembelajaran }\end{array}$ pendekatan saintifik pada kurikulum 2013 dari aspek perencanaan, proses pembelajaran, dan penilaian hasil belajar telah diatur dalam kebijakan yang disusun dalam Peraturan Menteri Pendidikan dan Kebudayaan Republik Indonesia. Perencanaan pelaksanaan pembelajaran (RPP) merupakan rancangan kegiatan yang akan dilakukan oleh guru selama pembelajaran tatap muka yang mengacu pada kompetensi yang diharapkan (Permendikbud RI No. 22 Tahun 2016). Pelaksanaan pembelajaran merupakan 
penerapan dari rencana guru dalam mengajar sehingga terjadi kegiatan untuk membelajarkan peserta didik (Dwiyogo, 2007: 174). Penilaian hasil belajar ialah mengumpulkan data mengenai kompetensi yang telah dimiliki oleh siswa setelah materi pembelajaran diberikan, yang dapat dilakukan dengan tes atau non tes (Winarno, 2014: 1). Dengan demikian untuk mengetahui pelaksanaan di lapangan dari standar atau kondisi yang ideal, maka perlu dilakukan evaluasi.

Kegiatan evaluasi merupakan bagian yang tidak dapat diabaikan dalam kelangsungan program yang berjalan, baik dalam program pendidikan maupun pembelajaran. Evaluasi diperlukan setiap kali intervensi baru sedang dicoba dan tidak diketahui apakah akan sesukses metode sebelumnya, atau program dapat ditingkatkan menjadi lebih baik dengan berbagai alternatif (Royse et al., 2010: 13). Tujuan utama evaluasi adalah untuk menentukan prestasi atau nilai termasuk membantu dalam pengambilan keputusan, meningkatkan program, organisasi, dan menambah pengetahuan (Fitzpatrick et al., 2011: 16). Dari data informasi yang tepat dan objektif dari program yang berjalan dapat dievaluasi untuk merumuskan keputusan (Widoyoko, 2013: 6). Dengan demikian dapat dikatakan bahwa evaluasi merupakan bagian yang harus dilakukan oleh seorang pendidik untuk meningkatkan kualitas pendidikan dan pembelajaran.

Berdasarkan wawancara kepada seorang guru PJOK di SMKN 4 Malang pada tanggal 9 November 2017 menyatakan bahwa penerapan Kurikulum 2013 di sekolah tersebut dilaksanaakan sejak 1 Juli 2013 dan guru PJOK selama ini telah mengikuti 3 sampai 4 kali pelatihan kurikulum 2013, menurutnya, kurikulum 2013 sangat sistematis mulai dari $\mathrm{KI} 1$, KI 2, KI 3, dan KI 4 serta Silabus dan RPP juga berurutan mulai pendahuluan, inti, dan penutup, serta penilaian berbasis otentik, penilaian sejawat, adapun sumber belajar yang digunakan siswa meliputi buku pegangan siswa, internet, youtube, siswa yang berprestasi, serta di sana fasilitas cukup memadai mulai internet, HP siswa, harapannya mengenai kurikulum 2013 perlu ditingkatkan lagi agar lebih dimodifikasi penilaiannya, serta pendekatan pembelajaran ke siswa agar lebih bervariasi dalam aktivitas gerak. Selanjutnya beliau juga menyampaikan bahwa RPP yang disusun oleh setiap guru sama semua dan sering melakukan team teaching karena demi memudahkan koordinasi dalam mengatasi benturan waktu pembelajaran dengan kegiatan di luar sekolah.

Dari hasil perubahan kurikulum secara nasional dengan kondisi lapangan yang terjadi di SMKN 4 Malang masih terjadi kesenjangan. Kurikulum 2013 yang telah direvisi pada tahun 2016 mengharapkan agar pembelajaran lebih berpusat pada siswa dan menuntut guru untuk kreatif dalam melakukan pembelajaran. Namun kenyataannya di SMKN 4 Malang RPP yang digunakan setiap guru sama dan sering melakukan pengajaran berbasis tim sebab guru di sana juga banyak tugas di luar sekolah, sehingga jumlah peserta didik akan menjadi lebih banyak daripada standar yang ada (gabungan dari dua sampai tiga kelas). Dengan demikian penerapan pendekatan saintifik PJOK akan tidak efektif dan efisien.

Berdasarkan permasalahan yang disajikan di atas, maka diperlukan evaluasi dalam pembelajaran PJOK dengan pendekatan saintifik pada kurikulum 2013 dengan bertujuan untuk mengetahui kesenjangan antara standar 
dengan pelaksanaan di lapangan. Dengan demikian maka model evaluasi yang digunakan adalah kesenjangan, yaitu mengukur tingkat kesenjangan antara standar dan penampilan untuk memberikan keputusan. Manfaat dari dilakukan evaluasi tersebut berfungsi agar program pembelajaran PJOK yang dilaksanakan dapat menjadi lebih baik serta lebih berstandar sesuai dengan yang diharapkan.

\section{METODE}

\begin{tabular}{lcc}
\multicolumn{2}{c}{ Penelitian evaluasi } & ini \\
denlakukan \\
dengan & pendekatan & deskriptif \\
kuantitatif. & Penelitian & evaluasi ini \\
dilakukan & untuk & mengungkap
\end{tabular} pembelajaran PJOK dengan pendekatan saintifik di SMK Negeri 4 Malang dengan model evaluasi discrepancy atau disebut kesenjangan (Fitzpatrick et al., 2011: 156). Model tersebut digunakan karena penelitian evaluasi ini hanya menitik beratkan pada tingkat kesenjangan pendekatan saintifik yang terjadi selama pembelajaran PJOK.

Waktu penelitian dilakukan selama bulan dari bulan November sampai Desember 2017. Penelitian ini dilakukan di SMK Negeri 4 Malang karena telah menerapkan kurikulum 2013.

Subjek Penelitian ini mengambil sampel sebanyak 3 Guru PJOK dan 191 siswa (yang juga diajar guru tersebut). Informasi yang diperoleh dari guru adalah RPP, kegiatan pengajaran, dan rancangan penilaian. Informasi yang diperoleh dari siswa adalah kegiatan pembelajaran dan penerapan penilaian yang dilakukan selama belajar. Teknik sampling purpusif dilakukan dalam pengambilan sampel, yaitu pemilihan sumber informasi Guru PJOK dipilih dengan pertimbangan peneliti. Dengan asumsi bahwa semua kemampuan Guru PJOK di SMKN 4 Malang memiliki tujuan dan pola pengajaran yang sama.
Prosedur penelitian meliputi penyusunan desain dengan menentukan kriteria evaluasi diperlukan antara lain: merumuskan tujuan, menyiapkan subjek, instrumen, dan menentukan kriteria pada sesuatu yang dapat diukur. Kemudian tahap pembuatan instrumen evaluasi untuk menilai tingkat kesenjangan dalam pelaksanaan pembelajaran. Setelah itu tahap pengumpulan data dari: RPP, rancangan penilaian, guru, dan siswa. Kemudian mengadakan analisis data dan menetapkan tingkat kesenjangan. Kemudian tahap membandingkan hasil analisis data yang telah diperoleh dengan kriteria yang telah dibuat. Selanjutnya pengambilan keputusan terhadap kesenjangan yang terjadi dalam pembelajaran PJOK di SMKN 4 Malang.

Data yang dianalisis dalam penelitian ini meliputi tiga aspek yaitu, (1) perencanaan pembelajaran, (2) proses pembelajaran, dan (3) penilaian hasil belajar. Pengumpulan data yang digunakan terdiri dari: telaah dokumen digunakan untuk menilai RPP beserta rancangan penilaiannya, kuesioner digunakan untuk mengkroscek pelaksanaan pembelajaran dan penilaian yang telah terjadi dari sudut pandang siswa. Observasi digunakan untuk pengambilan data dari mengamati kegiatan pembelajaran PJOK. Instrumen yang digunakan untuk pengambilan data menggunakan instrumen yang telah dibuat oleh (Mulyaningsih, 2015: 6066) yang telah teruji validitas dan reliabilitasnya yaitu meliputi: telaah dokumen, lembar observasi dan kuesioner untuk siswa.

Analisis data deskriptif kuantitatif dengan persentase digunakan untuk menentukan makna dalam penelitian ini. Teknik ini digunakan untuk menganalisis data yang diperoleh dari hasil telaah dokumentasi, lembar 
observasi, dan kuesioner dari siswa. Rumus yang digunakan untuk menganalisis data berupa deskriptif kuantitatif persentase dari (Sudijono, 2008: 43) dengan rumus sebagai berikut.

\section{Keterangan:}

$$
\mathrm{P}=\frac{f}{\mathrm{~N}} \times 100 \%
$$

$(f)$ = Jumlah skor yang didapat

(N) = Jumlah skor maksimal

(P) = Angka persentase

Hasil dari analisis data deskriptif kuantitatif kemudian diklasifikasikan dengan menggunakan kriteria penggolongan persentase pada Tabel 1 berikut.

Tabel 1. Kriteria Persentase

\begin{tabular}{cc}
\hline Persentase (\%) & Keterangan \\
\hline $80-100$ & sangat baik (SB) \\
\hline $66-79$ & baik (B) \\
\hline $56-65$ & cukup (C) \\
\hline $40-55$ & kurang (K) \\
\hline$<40$ & sangat kurang (SK) \\
\hline
\end{tabular}

(Sumber: Arikunto \& Jabar, 2009: 35)

\section{HASIL DAN PEMBAHASAN Perencanaan Pembelajaran}

Data hasil dari perencanaan pembelajaran PJOK diperoleh dari RPP yang dibuat oleh Guru PJOK di SMKN 4 Malang melalui lembar telaah dokumentasi. Dalam RPP mata pelajaran PJOK dengan pendekatan saintifik pada kurikulum 2013 terdiri dari 10 indikator antara lain: (1) identitas mata pelajaran, (2) indikator, (3) tujuan, (4) materi, (5) sumber belajar, (6) media yang digunakan, (7) model pembelajaran, (8) skenario pembelajaran, (9) pendekatan saintifik dalam pembelajaran, dan (10) rancangan penilaian. Berdasarkan hasil analisis data secara keseluruhan maka diperoleh persentase sebesar 83,33\% yang dapat digolongkan sangat baik dan memiliki tingkat kesenjangan $16,67 \%$. Berdasarkan rincian hasil analisis data dari RPP dengan telaah dokumentasi disajikan dalam Tabel 2 berikut.

Tabel 2. Hasil Analisis Data dari Telaah Dokumentasi tentang Perencanaan Pembelajaran dengan Sampel 3 RPP $(n=3)$

\begin{tabular}{clccccc}
\hline No & \multicolumn{1}{c}{ Indikator } & N & $\mathbf{f}$ & $\mathbf{P}(\%)$ & TK (\%) & Keterangan \\
\hline 1 & Identitas mata pelajaran & 12 & 11 & 91,67 & 8,33 & SB \\
2 & Perumusan indikator & 12 & 12 & 100 & 0 & SB \\
3 & Perumusan tujuan pembelajaran & 12 & 6 & 50 & 50 & K \\
4 & Pemilihan materi ajar & 12 & 10 & 83,33 & 16,67 & SB \\
5 & Pemilihan sumber belajar & 12 & 10 & 83,33 & 16,67 & SB \\
6 & Pemilihan media belajar & 12 & 10 & 83,33 & 16,67 & SB \\
7 & Pemilihan model pembelajaran & 12 & 10 & 83,33 & 16,67 & SB \\
8 & Skenario pembelajaran & 12 & 11 & 91,67 & 8,33 & SB \\
9 & Pelaksanaan pendekatan saintifik & 12 & 12 & 100 & 0 & SB \\
10 & Rancangan penilaian pembelajaran & 12 & 8 & 66,67 & 33,33 & B \\
\hline & Perencanaan Pembelajaran & $\mathbf{1 2 0}$ & $\mathbf{1 0 0}$ & $\mathbf{8 3 , 3 3}$ & $\mathbf{1 6 , 6 7}$ & SB \\
\hline
\end{tabular}

Keterangan: TK: tingkat kesenjangan

Pada aspek perencanaan pembelajaran, hasil temuan penelitian menunjukkan pada kategori sangat baik, namun pada indikator perumusan tujuan pembelajaran belum disajikan secara jelas dan konsisten. Dalam perencanaan pembelajaran perlu ditetapkan tujuan yang jelas sehingga tugas-tugas yang 
diberikan sesuai serta pertimbangan sisi abiotik (ruang, suhu, cuaca), dan jumlah siswa perlu dipertimbangkan sebab prinsip pertama dalam PJOK adalah keselamatan atau keamanan (Hopper et al., 2000: 114). Penggunaan tujuan pembelajaran sejalan dengan penilaian kompetensi yang dicapai, serta tujuan pembelajaran harus ditingkatkan secara bertahap berdasarkan umpan balik siswa (Khan et al., 2012: 44). Oleh karena itu tujuan pembelajaran hendaknya dituliskan sesuai dengan kompetensi dicapai dan kondisi lingkungan.

Temuan hasil studi menjelaskan bahwa pada RPP berbasis pendekatan saintifik mampu memberi motivasi dan menumbuhkan sikap intrinsik softskill pada peserta didik, sebab dengan melakukan tahap-tahap $5 \mathrm{M}$ dapat mendorong peserta didik dalam mengomunikasikan hasil temuannya dalam pembelajaran (Fauziah et al., 2017: 177). Selain itu pengetahuan guru dalam memodifikasi RPP berbasis pendekatan saintifik dapat memberikan efek yang baik bagi kemampuan mereka dalam menganalisis, menyusun instruksional, sintaksis, dan kontekstual pembelajaran (Nelson \& Davis, 2009: 52). Jadi dengan komponen RPP yang baik akan memberikan kemudahan bagi guru untuk melakukan proses pembelajaran.

Guru perlu ikut serta dalam pelatihan dan terus beradaptasi dalam pembuatan RPP mata pelajaran PJOK pada kurikulum 2013 terutama yang menekankan pada karakteristik pendekatan saintifik (Rahmat et al., 2019: 70). Dengan demikian setiap komponen RPP berbasis saintifik hendaknya dilengkapi dengan tepat sesuai anjuran kurikulum 2013, sebab RPP merupakan kerangka kerja guru sebelum menerapkan kegiatan belajar mengajar.

\section{Proses Pembelajaran}

Data hasil dari proses pembelajaran PJOK diperoleh dari pengajaran PJOK yang dilakukan oleh Guru terhadap siswa di SMKN 4 Malang melalui lembar observasi untuk guru dan kuesioner untuk siswa. Dalam variabel proses pembelajaran mata pelajaran PJOK dengan pendekatan saintifik pada kurikulum 2013 terdiri dari 3 indikator antara lain: (1) pendahuluan, (2) inti, (3) penutup. Berdasarkan hasil analisis data dari lembar observasi secara keseluruhan mengenai proses pembelajaran PJOK diperoleh persentase $87,04 \%$ sehingga dapat dikatakan sangat baik dan tingkat kesenjangan $12,96 \%$. Sedangkan hasil analisis data dari kuesioner siswa secara keseluruhan mengenai pelaksanaan pembelajaran PJOK diperoleh persentase sebesar $75,94 \%$ dengan kategori baik dan tingkat kesenjangan $24,06 \%$. Berdasarkan rincian data maka disajikan dalam Tabel 3 untuk lembar observasi dan Tabel 4 untuk kuesioner siswa.

Tabel 3. Hasil Analisis Data dari Lembar Observasi tentang Proses Pembelajaran dengan Sampel 3 Guru PJOK $(\mathrm{n}=3)$

\begin{tabular}{clccccc}
\hline No & Indikator & N & f & P (\%) & TK $(\%)$ & Keterangan \\
\hline 1 & Pendahuluan & 24 & 19 & 79,17 & 20,83 & B \\
2 & Inti & 72 & 65 & 90,28 & 9,72 & SB \\
3 & Penutup & 12 & 10 & 83,33 & 16,67 & SB \\
\hline & Jumlah & $\mathbf{1 0 8}$ & $\mathbf{9 4}$ & $\mathbf{8 7 , 0 4}$ & $\mathbf{1 2 , 9 6}$ & SB \\
\hline
\end{tabular}


Tabel 4. Hasil Analisis Data dari Kuesioner Siswa tentang Proses Pembelajaran dengan Sampel 191 Siswa $(n=191)$

\begin{tabular}{clccccc}
\hline No & Indikator & $\mathbf{N}$ & $\mathbf{f}$ & $\mathbf{P}(\boldsymbol{\%})$ & TK $(\boldsymbol{\%})$ & Keterangan \\
\hline 1 & Pendahuluan & 4584 & 3599 & 78,51 & 21,49 & $\mathrm{~B}$ \\
2 & Inti & 3820 & 2971 & 77,77 & 22,23 & $\mathrm{~B}$ \\
3 & Penutup & 2292 & 1553 & 67,76 & 32,24 & $\mathrm{~B}$ \\
\hline & Jumlah & $\mathbf{1 0 6 9 6}$ & $\mathbf{8 1 2 3}$ & $\mathbf{7 5 , 9 4}$ & $\mathbf{2 4 , 0 6}$ & $\mathbf{B}$ \\
\hline
\end{tabular}

Tabel 5. Hasil Analisis Data Proses Pembelajaran dari Gabungan Lembar Observasi dan Kuesioner Siswa

\begin{tabular}{clccc}
\hline No & Indikator & P (\%) & TK (\%) & Keterangan \\
\hline 1 & Pendahuluan & 78,84 & 21,16 & B \\
2 & Inti & 84,03 & 15,97 & SB \\
3 & Penutup & 75,55 & 24,45 & B \\
\hline & Proses Pembelajaran & $\mathbf{7 9 , 4 7}$ & $\mathbf{2 0 , 5 3 \%}$ & B \\
\hline
\end{tabular}

Proses pembelajaran yang dilaksanakan oleh SMK Negeri 4 Malang sudah tergolong baik dari aspek pendahuluan, inti, dan penutup. Namun guru perlu menyiapkan strategi agar dengan pendekatan saintifik tidak dominasi oleh peserta didik yang memiliki tingkat kognitif tinggi. Guru harus memahami keunikan individu selama mengajar siswa, sehingga dengan memperhatikan perbedaan dan keragaman mereka, guru harus melakukan pengajaran dan kegiatan di kelas secara individu (Rupani \& Bhutto, 2011: 126). Guru PJOK memiliki peran utama dalam memodifikasi dan mengadaptasi strategi pembelajaran secara fungsional dan struktural dalam menyampaikan materi pengajaran mereka (Palomares-Cuadros et al., 2018: 177). Oleh karena itu kualitas proses pembelajaran yang baik merupakan tanggung jawab seorang guru.

Hasil studi lain menunjukkan bahwa dalam penerapan pendekatan saintifik secara klasikal $85 \%$ peserta didik terlibat dalam pembelajaran serta hasil belajar dalam ranah kognitif, psikomotor, dan afektif berdampak positif, sehingga tujuan pembelajaran dapat tercapai (Machin, 2014: 34). Hasil tersebut juga selaras dengan penelitian ini yaitu selama kegiatan inti peserta didik diberikan kesempatan untuk mengamati materi gerakan teknik dalam olahraga. Kemudian diberikan kesempatan dalam bertanya, berdiskusi, berkolaborasi antar teman. Setelah konsep gerakan dalam materi paham kemudian guru memberikan kesempatan peserta didik untuk mempraktikkan gerakan secara berkelompok. Namun, dalam mengaplikasikan gerakan dalam bentuk permainan sederhana, hanya peserta didik yang berkemampuan gerak tinggi yang dapat menjalankan permainan tersebut. Hal tersebut menyebabkan peserta didik yang berkemampuan gerak yang rendah atau kurang terampil tidak begitu mendapatkan kesempatan bermain sama. Sehingga guru perlu memodifikasi bentuk permainan yang digunakan untuk mengaplikasikan ke dari konsep materi.

Temuan lain menyimpulkan bahwa pendekatan saintifik yang diterapkan dalam pembelajaran memberikan kesempatan peserta didik untuk berkomunikasi dengan temannya, sehingga mereka termotivasi untuk 
belajar dan mampu membentuk kepercayaan dirinya (Arlianty et al., 2017: 020084-7). Dalam pendekatan saintifik pada pembelajaran PJOK dapat melibatkan ranah kognitif yang lebih banyak sehingga ketika sedang diskusi dapat meningkatkan hubungan interaksi antar individu lain maupun lingkungannya (Raiola, 2017: 2239). PJOK merupakan pembelajaran di sekolah yang memberikan wadah bagi siswa dalam melakukan aktivitas jasmani untuk memperoleh tujuan pendidikan secara umum. Oleh karena itu, walaupun pembelajaran gerak melibatkan pendekatan saintifik, guru juga memperhitungkan juga bagaimana proses pembelajaran tetap memberikan aktivitas fisik yang cukup bagi seluruh peserta didik.

\section{Penilaian Pembelajaran}

Data hasil dari penilaian pembelajaran PJOK yang diperoleh dari rancangan penilaian dan proses penilaian hasil belajar dan yang dibuat dan dilaksanakan oleh Guru PJOK di SMKN 4 Malang melalui lembar telaah dokumentasi untuk guru dan kuesioner siswa. Dalam rancangan penilaian hasil belajar PJOK berbasis pendekatan saintifik terdiri dari 3 indikator antara lain: (1) karakteristik penilaian, (2) prinsip penilaian autentik, dan (3) teknik penilaian. Sedangkan proses penilaian hasil belajar mata pelajaran PJOK terdiri dari 3 indikator antara lain: (1) sikap, (2), pengetahuan, dan (3) keterampilan. Berdasarkan hasil analisis data dengan telaah dokumentasi terhadap sampel sebanyak 3 materi dalam instrumen penilaian secara keseluruhan maka diperoleh persentase sebesar 91,67\% dengan kategori sangat baik dengan tingkat kesenjangan 8,33\% . Sedangkan hasil analisis data dengan kuesioner dari siswa secara keseluruhan maka diperoleh persentase sebesar $61,97 \%$ dengan kategori cukup baik dengan tingkat kesenjangan 38,03\%. Berdasarkan rincian dari hasil analisis data maka disajikan dalam Tabel 6 untuk telaah dokumentasi dan Tabel 7 untuk kuesioner siswa.

Tabel 6. Hasil Analisis Data dari Telaah Dokumentasi dengan Sampel 3 Materi Instrumen Penilaian Hasil Belajar $(\mathrm{n}=3)$

\begin{tabular}{clccccc}
\hline No & \multicolumn{1}{c}{ Indikator } & N & f & P (\%) & TK (\%) & Keterangan \\
\hline 1 & Kesesuaian karakteristik penilaian & 12 & 12 & 100 & 0 & SB \\
2 & Kesesuaian prinsip penilaian otentik & 12 & 12 & 100 & 0 & SB \\
3 & Kesesuaian teknik penilaian & 12 & 9 & 75 & 25 & B \\
\hline & Jumlah & $\mathbf{3 6}$ & $\mathbf{3 3}$ & $\mathbf{9 1 , 6 7}$ & $\mathbf{8 , 3 3}$ & SB \\
\hline
\end{tabular}

Tabel 7. Hasil Analisis Data dari Kuesioner Siswa tentang Pelaksanaan Penilaian Hasil Belajar dengan Sampel 191 Siswa $(n=191)$

\begin{tabular}{clccccc}
\hline No & Indikator & N & f & P (\%) & TK (\%) & Keterangan \\
\hline 1 & Sikap & 1528 & 928 & 60,73 & 39,27 & C \\
2 & Pengetahuan & 1528 & 994 & 65,05 & 34,95 & B \\
3 & Keterampilan & 2292 & 1392 & 60,73 & 39,27 & C \\
\hline & Jumlah & $\mathbf{5 3 4 8}$ & $\mathbf{3 3 1 4}$ & $\mathbf{6 1 , 9 7}$ & $\mathbf{3 8 , 0 3}$ & C \\
\hline
\end{tabular}


Tabel 8. Hasil Analisis Data Penilaian Hasil Belajar dari Gabungan Telaah Dokumentasi dan Kuesioner Siswa

\begin{tabular}{clccc}
\hline No & \multicolumn{1}{c}{ Indikator } & P $(\%)$ & TK $(\%)$ & Keterangan \\
\hline 1 & Kesesuaian karakteristik penilaian & 100 & 0 & SB \\
2 & Kesesuaian prinsip penilaian otentik & 100 & 0 & SB \\
3 & Kesesuaian teknik penilaian & 75 & 25 & B \\
4 & Sikap & 60,73 & 39,27 & C \\
5 & Pengetahuan & 65,05 & 34,95 & B \\
6 & Keterampilan & 60,73 & 39,27 & C \\
\hline \multicolumn{2}{r}{ Penilaian Hasil Belajar } & $\mathbf{7 6 , 9 2}$ & $\mathbf{2 3 , 0 8}$ & B \\
\hline
\end{tabular}

Dari data pada aspek penilaian menunjukkan sudah tergolong baik, namun masih terdapat kekurangan pada indikator penilaian sikap dan keterampilan. Dalam PJOK, penting untuk menilai proses belajar mengajar terkait dengan hasil yang diharapkan, termasuk apa yang siswa dan guru lakukan dan bagaimana pelajaran disampaikan (McKenzie \& Lounsbery, 2013: 419). Guru dapat mengevaluasi pembelajaran berbasis kriteria dari hasil belajar peserta didik dalam pendekatan saintifik (Nelson \& Davis, 2012: 1931).

Dalam pendekatan saintifik penilaian tidak hanya valid dan reliabel, tetapi juga autentik, bermakna, dan relevan dengan usia dan perkembangan peserta didik serta memungkinkan penilaian proses untuk memfasilitasi pengajaran yang lebih informatif, sehingga program pembelajaran lebih efektif (Lander et al., 2017: 293). Dengan penilaian autentik akan mendorong peserta didik untuk aktif dalam pembelajaran dan mampu meningkatkan hasil belajar mereka (Chong et al., 2016: 125). Penilaian autentik dalam pendekatan saintifik melibatkan sikap, pengetahuan, dan keterampilan bagi siswa yang dapat mencerminkan kehidupan nyata (Raymond et al., 2013: 471). Dari beberapa temuan penelitian lain tersebut memberikan penegasan bahwa penilaian tidak hanya mengungkap informasi dari kompetensi siswa, namun juga memberi dapat memberikan motivasi siswa untuk terus meningkatkan kompetensi mereka secara berkelanjutan.

Hasil temuan dalam penelitian ini menunjukkan bahwa rancangan penilaian sikap, pengetahuan, dan keterampilan telah tersusun. Namun dari sudut pandang peserta didik aspek penilaian sikap dan keterampilan masih tergolong cukup. Hasil cukup tersebut disebabkan penilaian sikap dan keterampilan belum secara konsisten dilakukan, diantaranya: pada penilaian sikap guru masih belum memberikan kesempatan peserta didik menilai diri sendiri dan teman sebaya, penilaian keterampilan belum melibatkan karyakarya dari peserta didik. Penilaian keterampilan yang menggabungkan metode tradisional (tes praktik) dan alternatif seperti pengumpulan karyakarya dari peserta didik lebih efektif dalam memberikan informasi pada kompetensi yang dimiliki (Mogonea, 2015: 864). Selain itu, dengan memberikan berbagai penilaian yang bervariasi akan membuat dokumen penilaian hasil belajar lebih valid dan kredibel (Mustafa et al., 2019: 1377). Dengan demikian penerapan pendekatan saintifik pada aspek penilaian siswa tidak hanya mengandalkan dari tes praktik saja, namun juga perlu penilaian alternatif lain untuk menilai keterampilan.

Berdasarkan hasil analisis secara keseluruhan kualitas pelaksanaan 
pembelajaran PJOK dengan pendekatan saintifik pada kurikulum 2013 di SMKN 4 Malang memiliki persentase sebesar $79,91 \%$ dengan kategori baik dan tingkat kesenjangan 20,09\%. Hasil rincian analisis data mengenai pelaksanaan pembelajaran PJOK dengan pendekatan saintifik kurikulum 2013 di SMKN disajikan dalam Tabel 9 berikut.

Tabel 9. Pelaksanaan Pembelajaran PJOK dengan Pendekatan Saintifik

\begin{tabular}{llccc}
\hline \multicolumn{1}{c}{ Konsep } & \multicolumn{1}{c}{ Variabel } & P $(\boldsymbol{\%})$ & TK (\%) & Keterangan \\
\hline Pembelajaran PJOK & Perencanaan Pembelajaran & 83,33 & 16,67 & SB \\
dengan Pendekatan & Proses Pembelajaran & 79,47 & 20,53 & B \\
Saintifik & Penilaian Hasil Belajar & 76,92 & 23,08 & B \\
\hline & Rata-Rata & $\mathbf{7 9 , 9 1}$ & $\mathbf{2 0 , 0 9}$ & B \\
\hline
\end{tabular}

Berdasarkan analisis data keseluruhan secara kuantitatif dari aspek perencanaan, proses pelaksanaan pembelajaran, dan penilaian hasil belajar bahwa pendekatan saintifik dalam pembelajaran PJOK di SMK Negeri 4 Malang sudah tergolong baik. Dalam proses pembelajaran dan penilaian hasil belajar sebaiknya selaras dengan apa yang direncanakan. Pada proses pembelajaran dengan pendekatan saintifik peserta didik diberikan kesempatan untuk membentuk pengetahuan mereka secara ilmiah kemudian guru memvalidasi melalui umpan balik yang diberikan (Musfiqon \& Nurdyansyah, 2015: 65). Pengetahuan baru yang dibentuk oleh peserta didik merupakan tujuan dari pembelajaran tersebut.

Pembelajaran PJOK dengan pendekatan saintifik dapat meningkatkan kecerdasan spasial siswa (Tarigan et al., 2018: 140). Namun, ada kendala yang sering dihadapi guru dalam menerapkan pendekatan saintifik dalam pembelajaran yaitu keterbatasan waktu (Mulyaningsih \& Kartowagiran, 2015: 77). Selain itu, dalam pembelajaran PJOK tidak selamanya pencapaian peserta didik tuntas semua, sebab setiap siswa memiliki beragam kemampuan dalam melakukan aktivitas fisik (Hariyanto \& Mustafa, 2020: 29; Mustafa \& Winarno, 2020: 2). Dalam kurikulum 2013 PJOK di tingkat SMA/SMK memiliki jumlah jam belajar 135 menit per minggu. Dengan alokasi waktu yang terbatas tersebut membuat pelaksanaan di lapangan belum sesuai dengan perencanaan.

Kendala teknis selama pembelajaran berlangsung merupakan tantangan bagi guru untuk meningkatkan keterampilan mereka dalam mendesain pembelajaran, sehingga mereka dapat menganalisis bagaimana peserta didik belajar, dan menyusun strategi yang sesuai untuk mengembangkan kompetensi peserta didik (Holmqvist \& Olander, 2017). Hasil belajar dalam kurikulum PJOK di era abad 21 tidak hanya terampil dan terlatih dalam aktivitas fisik, melainkan juga mampu berpikir kreatif, kritis, berkolaborasi, serta memiliki karakter yang baik (Mustafa \& Dwiyogo, 2020: 422). Pendekatan saintifik merupakan salah satu alternatif yang dapat digunakan dalam pembelajaran PJOK. Keberhasilan pembelajaran saintifik sejatinya juga dipengaruhi oleh kondisi peserta didik (Wicaksono et al., 2020: 41). Namun, dengan adanya menerapkan pendekatan saintifik memberikan siswa lebih termotivasi dan percaya diri dalam belajar (Safitri \& Widjajanti, 2019: 1). Setiap peserta didik itu unik dan memiliki kelebihan dan kekurangan, sehingga dengan 
alternatif pendekatan saintifik peserta didik dilibatkan secara aktif untuk saling berinteraksi antar teman maupun guru. Selama menggunakan pendekatan saintifik dalam pembelajaran, guru perlu mendokumentasikan setiap prestasi yang dimiliki oleh peserta didik. Sehingga penilaian hasil peserta didik merupakan gambaran mereka secara utuh selama mengikuti pembelajaran.

\section{SIMPULAN DAN SARAN}

Kesimpulan mengenai kualitas pelaksanaan pembelajaran PJOK dengan pendekatan saintifik pada SMKN 4 Malang memiliki kategori baik. Kualitas perencanaan pembelajaran PJOK dengan pendekatan saintifik mendapatkan kategori sangat baik, namun perlu perbaikan khususnya dalam merumuskan tujuan pembelajaran PJOK perlu disajikan. Dalam kualitas proses pembelajaran PJOK dengan pendekatan mendapatkan kategori baik, namun perlu perbaikan khususnya dalam pengelolaan waktu dan proses pembelajaran harus saling dikaitkan antar materi serta tujuan yang dicapai harus diberitahukan kepada siswa. Dalam kualitas penilaian hasil belajar PJOK dengan pendekatan saintifik mendapatkan kualitas baik, namun perlu perbaikan khususnya dalam variasi jenis penilaian yang dilakukan mulai ranah sikap, pengetahuan, dan keterampilan.

Rekomendasai dari hasil evaluasi mengenai pelaksanaan pembelajaran PJOK dengan pendekatan saintifik di SMKN 4 Malang, antara lain: (1) aspek perencanaan pembelajaran seharusnya: jumlah pertemuan dengan alokasi waktu disesuaikan, dirumuskan tujuan pembelajaran dengan jelas dan spesifik, disajikan konsep materi pembelajaran dengan spesifik, dalam skenario pembelajaran alokasi waktu disesuaikan dengan di poin identitas mata pelajaran, instrumen penilaian sikap disesuaikan dengan indikator yang dicapai; (2) aspek proses pembelajaran hendaknya: guru mengaitkan dengan materi sebelumnya, guru menjelaskan tujuan, manfaat, dan kompetensi yang hendak dicapai dalam materi pembelajaran; dan (3) aspek penilaian hasil belahar sebaiknya: penilaian menggunakan teknik yang bervariasi untuk mendokumentasikan kompetensi siswa selama pembelajaran. Selain itu rekomendasi yang dianjurkan sebaiknya guru aktif dalam mengikuti pelatihan pembelajaran kurikulum 2013 dan senantiasa terus beradaptasi mengenai kebaruan pola pembelajaran yang terus berkembang.

\section{DAFTAR PUSTAKA}

Arifin, Z. (2013). Konsep dan Model Pengembangan Kurikulum. Bandung: PT. Remaja Rosdakarya. Arikunto, S., \& Jabar, C. S. A. (2009). Evaluasi Program Pendidikan: Pedoman Teoretis Praktis bagi Mahasiswa dan Praktisi Pendidikan. Jakarta: Bumi Aksara. Arlianty, W. N., Febriana, B. W., \& Diniaty, A. (2017). An analysis of learning process based on scientific approach in physical chemsitry experiment. In AIP Conference Proceedings (Vol. 1823, hal. 020084). https://doi.org/10.1063/1.4978157

Basuki, S. (2016). Pendekatan Saintifik pada Penjasorkes dalam Rangka Membentuk Jati Diri Peserta Didik. Jurnal Pendidikan Jasmani Indonesia, 12(2), 117-124.

BSNP. Peraturan Menteri Pendidikan dan Kebudayaan Nomor 22 Tahun 2016 tentang Standar Proses Pendidikan Dasar dan Menengah (2016).

BSNP. Undang-Undang Republik 
Indonesia Nomor 20 Tahun 2003 tentang Sistem Pendidikan Nasional, Pub. L. No. 20 (2016). Indonesia:

http://kelembagaan.ristekdikti.go.i d/wpcontent/uploads/2016/08/UU_no_2 0_th_2003.pdf.

Chandler, T., Cronin, M., \& Vamplew, W. (2002). Sport and Physical Education: The Key Concepts. Abingdon, UK: Taylor \& Francis. https://doi.org/10.4324/978020346 7145

Chong, E. J. M., Lim, J. S. W., Liu, Y., Lau, Y. Y. L., \& Wu, V. X. (2016). Improvement of learning domains of nursing students with the use of authentic assessment pedagogy in clinical practice. Nurse Education in Practice, 20, 125-130. https://doi.org/10.1016/j.nepr.2016 .08 .002

Dharmadi, M. A. (2016). The Analysis of School Health Development Index (SHDI). Jurnal Kesehatan Masyarakat, 12(1), 11-17. https://doi.org/10.15294/kemas.v1 $2 \mathrm{i} 1.4021$

Dwiyogo, W. D. (2007). Pengembangan Kurikulum dan Pembelajaran Pendidikan Jasmani dan Olahraga. Malang: Wineka Media.

Fauziah, R., Abdullah, A. G., \& Hakim, D. L. (2017). Pembelajaran Saintifik Elektronika Dasar Berorientasi Pembelajaran Berbasis Masalah. Innovation of Vocational Technology Education, 9(2), 165-178. https://doi.org/10.17509/invotec.v9 i2.4878

Fitzpatrick, J. L., Sanders, J. R., \& Worthen, B. R. (2011). Program Evaluation: Alternative Approaches and Practical Guidelines. Boston: Pearson.
Hariyanto, E., \& Mustafa, P. S. (2020). Pengajaran Remedial dalam Pendidikan Jasmani. (Mashud, Ed.). Banjarmasin: Lambung Mangkurat University Press.

Holmqvist, M. O., \& Olander, C. (2017). Analysing teachers' operations when teaching students: what constitutes scientific theories? International Journal of Science Education, 39(7), 840862.

https://doi.org/10.1080/09500693.2 017.1310407

Hopper, B., Grey, J., \& Maude, T. (2000). Teaching Physical Education in the Primary School. New York: RoutledgeFalmer.

Khan, T., Hande, S., Bedi, S., Singh, T., \& Kumar, V. (2012). Learning Objectives. International Journal of User-Driven Healthcare, 2(3), 44-62.

https://doi.org/10.4018/ijudh.2012 070105

Kirk, D. (2013). Educational Value and Models-Based Practice in Physical Education. Educational Philosophy and Theory, 45(9), 973-986. https://doi.org/10.1080/00131857.2 013.785352

Lander, N., Morgan, P. J., Salmon, J., Logan, S. W., \& Barnett, L. M. (2017). The reliability and validity of an authentic motor skill assessment tool for early adolescent girls in an Australian school setting. Journal of Science and Medicine in Sport, 20(6), 590594.

https://doi.org/10.1016/j.jsams.201 6.11 .007

Machin, A. (2014). Implementasi Pendekatan Saintifik, Penanaman Karakter dan Konservasi pada Pembelajaran Materi Pertumbuhan. Jurnal Pendidikan IPA Indonesia, $3(1)$, 28-35. 
https://doi.org/10.15294/jpii.v3i1.2 898

Martinek, T., \& Hellison, D. (2009). Youth Leadership in Sport and Physical Education. New York: Palgrave Macmillan.

McKenzie, T. L., \& Lounsbery, M. A. F. (2013). Physical education teacher effectiveness in a public health context. Research Quarterly for Exercise and Sport, 84(4), 419430.

https://doi.org/10.1080/02701367.2 013.844025

Mogonea, F. (2015). Portfolio-tool for (Self) Evaluation of Studentsfuture Teachers. Procedia - Social and Behavioral Sciences, 180(November 2014), 860-864. https://doi.org/10.1016/j.sbspro.20 15.02.227

Mulyaningsih, N. (2015). Evaluasi Pelaksanaan Pembelajaran Pendidikan Agama Islam dan Budi Pekerti dengan Pendekatan Saintifik Pada Kurikulum 2013 di SMA Kota Yogyakarta. Yogyakarta: UNY.

Mulyaningsih, N., \& Kartowagiran, B. (2015). Evaluasi Pelaksanaan Pembelajaran PAI dan Budi Pekerti dengan Pendekatan Saintifik pada Kurikulum 2013. Jurnal Evaluasi Pendidikan, 3(1), 67-79.

Musfiqon, H., \& Nurdyansyah. (2015). Pendekatan Pembelajaran Saintifik. Sidoarjo: Nizamia Learning Center.

Mustafa, P. S., \& Dwiyogo, W. D. (2020). Kurikulum Pendidikan Jasmani, Olahraga, dan Kesehatan di Indonesia Abad 21. Jurnal Riset Teknologi dan Inovasi Pendidikan (JARTIKA), 3(2), 422-438. https://doi.org/https://doi.org/10.36 765/jartika.v3i2.268

Mustafa, P. S., \& Winarno, M. E.
(2020). Pengembangan Buku Ajar Pengajaran Remedial dalam Pendidikan Jasmani untuk Mahasiswa S1 Pendidikan Jasmani Dan Kesehatan Universitas Negeri Malang. Multilateral: Jurnal Pendidikan Jasmani dan Olahraga, 19(1), 1-12. https://doi.org/10.20527/multilater al.v19i1.7629

Mustafa, P. S., Winarno, M. E., \& Supriyadi. (2019). Penilaian Pendidikan Jasmani, Olahraga, dan Kesehatan pada Sekolah Menengah Pertama Negeri Kota Malang. Jurnal Pendidikan: Teori, Penelitian, dan Pengembangan, 4(10), 1364-1379. https://doi.org/http://dx.doi.org/10. 17977/jptpp.v4i10.12845

Nelson, M. M., \& Davis, E. A. (2009). Preservice elementary teachers' science lesson plan analyses and modifications concerning scientific modeling: Insights into teacher knowledge application. In Annual Conference ofthe National Association for Research in Science Teaching. Garden Grove: CA.

https://doi.org/10.1017/CBO97811 07415324.004

Nelson, M. M., \& Davis, E. A. (2012). Preservice Elementary Teachers' Evaluations of Elementary Students' Scientific Models: An aspect of pedagogical content knowledge for scientific modeling. International Journal of Science Education, 34(12), 1931-1959. https://doi.org/10.1080/09500693.2 011.594103

Palomares-Cuadros, J., Dharmadi, M. A., Sulistia-Dewi, N. L. P. E., Collado-Fernández, D., \& PadialRuz, R. (2018). Teacher beliefs in the diffusion of traditional Buleleng-Bali games. Revista 
Brasileira de Ciencias do Esporte, 40(2), 177-183. https://doi.org/10.1016/j.rbce.2018. 01.018

Rahmat, R., Suwardi, S., \& Suyudi, I. (2019). Implementasi Pendekatan Saintifik Pada Pembelajaran Pendidikan Jasmani Olahraga Dan Kesehatan (PJOK) SD Kurikulum 2013 Di Kabupaten Bantaeng. SPORTIVE: Journal Of Physical Education, Sport and Recreation, 2(2), 63-72. https://doi.org/10.26858/sportive.v 2i 2.9502

Raiola, G. (2017). Motor learning and teaching method. Journal of Physical Education and Sport, 17(5), 2239-2243. https://doi.org/10.7752/jpes.2017.s 5236

Raymond, J. E., Homer, C. S. E., Smith, R., \& Gray, J. E. (2013). Learning through authentic assessment: An evaluation of a new development in the undergraduate midwifery curriculum. Nurse Education in Practice, 13(5), 471-476. https://doi.org/10.1016/j.nepr.2012 .10 .006

Royse, D., Thyer, B. A., \& Padgett, D. K. (2010). Program Evaluation: An Introduction (5 ed.). Australia: Wadsworth, Cengage Learning.

Rupani, C. M., \& Bhutto, M. I. (2011). Evaluation of Existing Teaching Learning Process on Bloom'S Taxonomy. International Journal of Academic Research in Business and Social Sciences, 1(Special Issue), 119-128.

Safitri, R. E., \& Widjajanti, D. B. (2019). The effect of inquiry in scientific learning on students' self-confidence. Journal of Physics: Conference Series, 1157(4), 042073. https://doi.org/10.1088/1742-
6596/1157/4/042073

Sani, R. A. (2014). Pembelajaran Saintifik untuk Implementasi Kurikulum 2013. Jakarta: PT Bumi Aksara.

Sudijono, A. (2008). Pengantar Statistik Pendidikan. Jakarta: PT Raja Grafindo Persada.

Tarigan, B., Hendrayana, Y., \& Wijayanti, K. E. (2018). Implementasi Pendekatan Saintifik Dalam Pembelajaran Pendidikan Jasmani Dan Olahraga: Dapatkah meningkatkan Konsentrasi Dan Kecerdasan Spasial (Spatial Intelegence) Siswa Sekolah Dasar Yang Tinggal Di Daerah Pegunungan. Jurnal Pendidikan Jasmani dan Olahraga, 3(2), 136141. https://doi.org/10.17509/jpjo.v3i2. 12476

Whitehead, J., Telfer, H., \& Lambert, J. (2013). Values in Youth Sport and Physical Education. London: Routledge.

https://doi.org/10.4324/978020311 4155

Wicaksono, P. N., Kusuma, I. J., Festiawan, R., Widanita, N., \& Anggraeni, D. (2020). Evaluasi penerapan pendekatan saintifik pada pembelajaran pendidikan jasmani materi teknik dasar passing sepak bola. Jurnal Pendidikan Jasmani Indonesia, 16(1), 41-54. https://doi.org/https://doi.org/10.21 831/jpji.v16i1.29774

Widoyoko, S. E. P. (2013). Evaluasi Program Pembelajaran: Panduan Praktis bagi Pendidik dan Calon Pendidik. Yogyakarta: Pustaka Pelajar.

Winarno, M. E. (2012). Pengembangan Karakter Bangsa melalui Pendidikan Jasmani \& Rohani. Malang. 
Winarno, M. E. (2014). Evaluasi Hasil Belajar Pendidikan Jasmani Olahraga dan Kesehatan. Malang: Universitas Negeri Malang.

Wiyanto. (2017). Pendekatan Saintifik pada Perkuliahan dengan Sistem ELearning. Jurnal INTEGRALISTIK, 28(2), 217-229. https://doi.org/10.15294/integralisti k.v28i2.13738 